\title{
Cytotaxonomy of the Maculata subcomplex (Hemiptera, Triatominae)
}

\author{
C. H. L. Imperador ${ }^{a}$, F. F. F. Moreira ${ }^{b}$, J. A. Rosa ${ }^{c}$, M. T. V. Azeredo-Oliveira ${ }^{a}$ and \\ K. C. C. Alevia*
}

aLaboratório de Biologia Celular, Departamento de Biologia, Instituto de Biociências, Letras e Ciências Exatas - IBILCE, Universidade Estadual Paulista "Júlio de Mesquita Filho" - UNESP, Rua Cristóvão Colombo, 2265, Jardim Nazareth, CEP 15054-000, São José do Rio Preto, SP, Brazil

'Laboratório Nacional e Internacional de Referência em Taxonomia de Triatomíneos, Instituto Oswaldo Cruz - FIOCRUZ, Av. Brasil, 4365, Pavilhão Rocha Lima, $5^{\circ}$ andar, Manguinhos, CEP 21045-900, Rio de Janeiro, RJ, Brazil

'Laboratório de Parasitologia, Departamento de Ciências Biológicas, Faculdade de Ciências Farmacêuticas - FCFAR, Universidade Estadual Paulista “Júlio de Mesquita Filho” - UNESP, Rodovia Araraquara-Jaú, Km 1, CEP 14801-902, Araraquara, SP, Brazil

*e-mail: kaiochaboli@hotmail.com

Received: December 15, 2015 - Accepted: June 2, 2016 - Distributed: November 31, 2017

(With 1 figure)

\section{Scientific Note}

Triatomines are hematophagous insects belonging to the Hemiptera order and Triatominae subfamily. All members of this subfamily are potential vectors of Chagas disease (Tartarotti et al., 2006). The Maculata subcomplex is composed of four species: Triatoma maculata, T. pseudomaculata, T. arthurneivai and T. wygodzinskyi. Recent phylogenetic analyzes showed conflicting results in relation to monophyly of this complex, because Justi et al. (2014) have failed to rescue the monophyly of the subcomplex and observed that T. maculata was more related to the species of the Brasiliensis subcomplex than the species of Maculata subcomplex (T. arthurneivai was not used in the study).

By means of cytogenetic characterization of the spermatocytes (prophase I), Santos et al. (2007) proposed that T. maculata, T. pseudomaculata and T. arthurneivai presented different heterochromatin patterns distribution and meiotic behavior. Panzera et al. (2010) describe the pattern heterochromatic of T. wygodzinskyi as identical to that observed for T. arthurneivai. However, Carbajal-de-La-Fuente et al. (2010) highlight that in many works of literature T. wygodzinskyi was erroneously classified as T. arthurneivai. Thus, this work describes the heterochromatic pattern of all species of the Maculata subcomplex, with cytotaxonomic focus.

At least two males from each species were used. They had been assigned by the FCFAR/UNESP, Araraquara, São Paulo, Brazil, FIOCRUZ, Rio de Janeiro, Brazil and CPqRR-FIOCRUZ, Minas Gerais, Brazil. The seminiferous tubules of adult males were torn and fixed to a cover slip. They then underwent the cytogenetic technique of C-banding (Sumner, 1972) and analyzed using a Jenaval light microscope (Zeiss).

By analyzing of the distribution of the pattern of constitutive heterochromatin in spermatocytes in prophase I has been possible to differentiate all species of Maculata subcomplex: T. maculata (Figure 1A) showed a heterochromatic chromocenter formed by the sex chromosomes (arrow) and small heterochromatic blocks dispersed in nucleus;
T. pseudomaculata (Figure 1B) showed a heterochromatic chromocenter formed by the sex chromosomes plus one pair of autosomes (arrow) and some heterochromatic blocks dispersed in the nucleus; T. wygodzinskyi (Figure 1C) showed only one heterochromatic chromocenter formed by the sex chromosomes (arrow) and T. arthurneivai (Figure 1D) showed a heterochromatic chromocenter formed by the sex chromosomes (arrow) and large heterochromatic blocks dispersed in the nucleus.

Schofield (1988) suggests that T. maculata and T. pseudomaculata species are derived from a common ancestor that was dispersed passively through the feathers of migratory birds and isolated geographically. These species are very similar from the morphological point of view (Corrêa and Espinola, 1964) and cytogenetic analysis described above confirm the data initially described by Santos et al. (2007) and corroborate the specific status of these triatomines. We suggest that during the speciation of $T$. pseudomaculata, heterochromatin loss events were involved in genomic reorganization with loss of heterochromatin, as has been observed for the pallescens group (Alevi et al., 2015).

The phylogenetic relationship between T. maculata and Brasiliensis subcomplex reported by Justi et al. (2014) can be confirmed by standard heterochromatin of the species. However, the meiotic behavior of these vectors is different, since during prophase T. maculata, the chromocenter is formed by sex chromosomes, different of the species the Brasiliensis subcomplex which has the chromocenter form by sex chromosomes plus one pair of autosomes.

T. wygodzinskyi was described based on specimens collected in Santa Rita de Caldas, in southern Minas Gerais, Brazil and initially classified as T. arthurneivai (Lent, 1951). Different from the cytogenetic characteristics described initially, our results show that these species display large differences in heterochromatic pattern being the genetic material of $T$. arthurneivai rich in constitutive heterochromatin. Thus, we emphasize that the specimens 

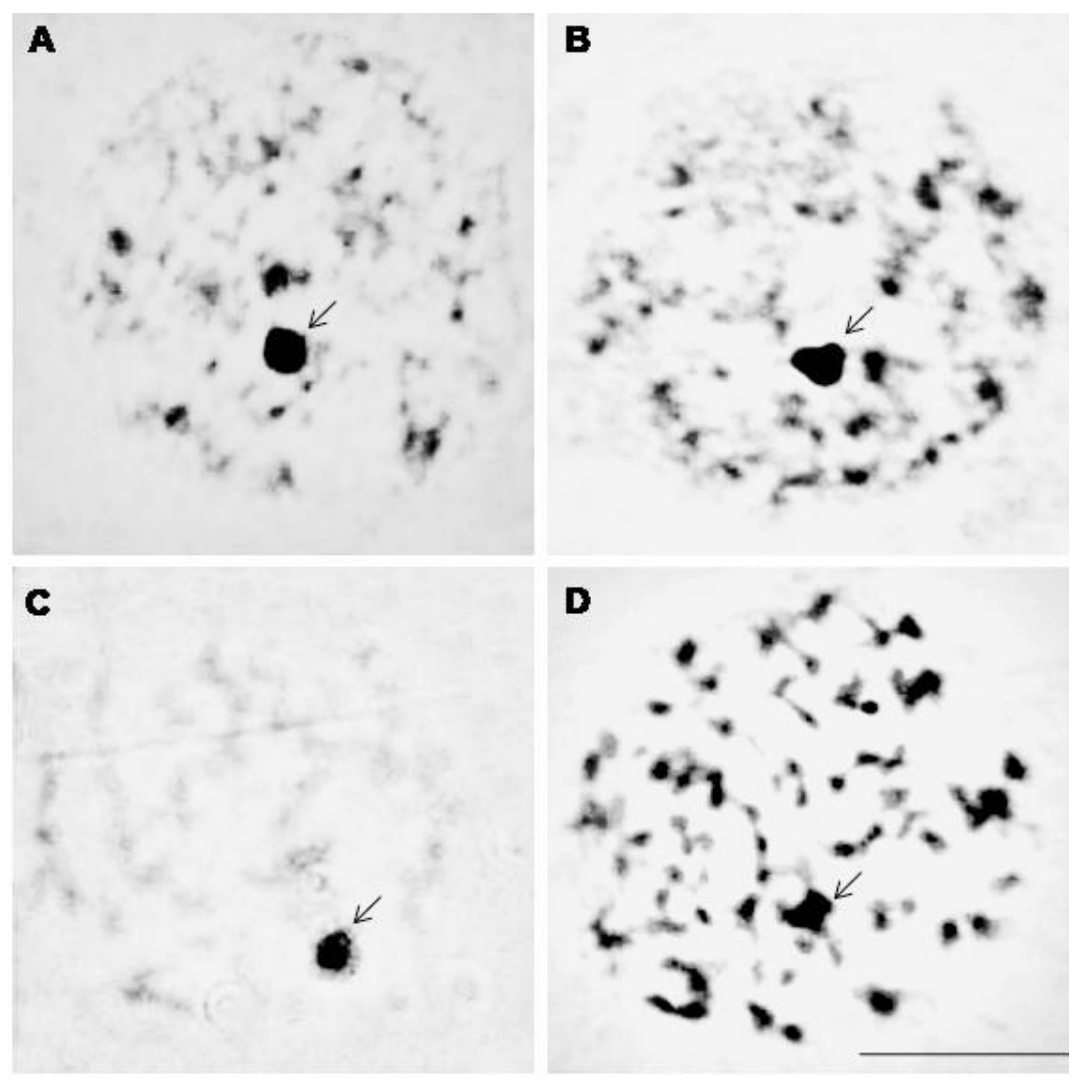

Figure 1. Constitutive heterochromatin in spermatocytes (prophase I) of all species of Maculata subcomplex. (A) Note the heterochromatic chromocenter formed by the sex chromosomes (arrow) and small heterochromatic blocks dispersed in T. maculata; (B) Note the heterochromatic chromocenter formed by the sex chromosomes plus one pair of autosomes (arrow) and some heterochromatic blocks dispersed in T. pseudomaculata; (C) Note witch only one heterochromatic chromocenter formed by the sex chromosomes (arrow) in T. wygodzinskyi; (D) Note the heterochromatic chromocenter formed by the sex chromosomes (arrow) and large heterochromatic blocks dispersed in T. arthurneivai. Bar: $10 \mu \mathrm{m}$.

analyzed by Santos et al. (2007) were T. wygodzinskyi and not $T$. arthurneivai as classified by the authors.

Thus, in the present study demonstrated that the analysis of heterochromatic pattern is a cytotaxonomic tool of utmost importance to characterize the species of Maculata subcomplex.

\section{Acknowledgements}

We are grateful to the agencies FAPESP (processes $n^{\circ}$ 2013/19764-0) and CNPq.

\section{References}

ALEVI, K.C.C., RAVAZI, A., FRANCO-BERNARDES, M.F., ROSA, J.A. and AZEREDO-OLIVEIRA, M.T.V., 2015. Chromosomal evolution in the pallescens group (Hemiptera, Triatominae). Genetics and Molecular Research, vol. 14, no. 4, pp. 12654-12659. PMid:26505416. http://dx.doi.org/10.4238/2015. October.19.9.

CARBAJAL-DE-LA-FUENTE, A.L., JARAMILLO, N., BARATA, J.M.S., NOIREAU, F. and DIOTAIUTI, L., 2010. Misidentification of two Brazilian triatomes, Triatoma arthurneivai and Triatoma wygodzinskyi, revealed by geometric morphometrics. Medical and Veterinary Entomology, vol. 25, no. 2, pp. 178-183. PMid:21039685. http://dx.doi.org/10.1111/j.1365-2915.2010.00912.x.

CORRÊA, R.R. and ESPÍNOLA, H.N., 1964. Descrição de Triatoma pseudomaculata, nova espécie de triatomíneo de Sobral. Ceará. Arquivos de Higiene e Saude Publica, vol. 29, no. 101, pp. 115-127. PMid:4959506.

JUSTI, S.A., RUSSO, C.A.M., MALLET, J.R.S., OBARA, M.T. and GALVÃO, C., 2014. Molecular phylogeny of Triatomini (Hemiptera: Reduviidae: Triatominae). Parasites \& Vectors, vol. 7, no. 1, pp. 149. PMid:24685273. http://dx.doi.org/10.1186/17563305-7-149.

LENT, H., 1951. Novo Triatoma no Estado de Minas Gerais (Brasil) (Hemiptera: Reduviidae). Revista de Entomologia, vol. 22, no. 1-3, pp. 349-353.

PANZERA, F., PÉREZ, R., PANZERA, Y., FERRANDIS, I., FERREIRO, M.J. and CALLEROS, L., 2010. Cytogenetics and genome evolution in the subfamily Triatominae (Hemiptera, Reduviidae). Cytogenetic and Genome Research, vol. 128, no. 1-3, pp. 77-87. PMid:20407223. http://dx.doi.org/10.1159/000298824.

SANTOS, S.M., LOPES, C.M., DUJARDIN, J.P., PANZERA, F., PEREZ, R., CARBAJAL DE LA FUENTE, A.L., PACHECO, 
R.S. and NOIREAU, F., 2007. Evolutionary relationships based on genetic and phenetic characters between Triatoma maculata, Triatoma pseudomaculata and morphologically related species (Reduviidae: Triatominae). Infection, Genetics and Evolution, vol. 7, no. 4, pp. 469-475. PMid:17336167. http://dx.doi.org/10.1016/j. meegid.2007.01.008.

SCHOFIELD, C.J., 1988. Biosystematics of the Triatominae. In: M.W. SERVICE. Biosystematics of haematophagous insects. Oxford: Clarendon Press, pp. 284-312.
SUMNER, A.T., 1972. A simple technique for demonstrating centromeric heterochromatin. Experimental Cell Research, vol. 75, no. 1, pp. 304-306. PMid:4117921. http://dx.doi.org/10.1016/00144827(72)90558-7.

TARTAROTTI, E., AZEREDO-OLIVEIRA, M.T.V. and CERON, C.R., 2006. Phylogenetic approach to the study of triatomines (Triatominae, Heteroptera). Brazilian Journal of Biology $=$ Revista Brasileira de Biologia, vol. 66, no. 2B, pp. 703-708. http://dx.doi. org/10.1590/S1519-69842006000400014. 